\title{
Maternal Anthropometric Study of Low Birth Weight Newborns in Saudi Arabia: A Hospital-Based Case-Control Study
}

\author{
Abdullah G. Alkushi1 ${ }^{*}$, Naser A. El Sawy² \\ ${ }^{1}$ Department of Anatomy, Faculty of Medicine, Umm Al Qura University, Mecca, Saudi Arabia \\ ${ }^{2}$ Department of Anatomy and Embryology, Faculty of Medicine, Zagazig University, Zagazig, Egypt \\ Email: ^dr.alkushi@gmail.com,naser_elsawy@ymail.com
}

How to cite this paper: Alkushi, A.G. and El Sawy, N.A. (2016) Maternal Anthropometric Study of Low Birth Weight Newborns in Saudi Arabia: A Hospital-Based Case-Control Study. Advances in Reproductive Sciences, 4, 101-113.

http://dx.doi.org/10.4236/arsci.2016.44012

Received: August 20, 2016

Accepted: September 24, 2016

Published: September 27, 2016

Copyright $\odot 2016$ by authors and Scientific Research Publishing Inc. This work is licensed under the Creative Commons Attribution International License (CC BY 4.0).

http://creativecommons.org/licenses/by/4.0/ (c) (†) Open Access

\section{Abstract}

Background: The aim of the study is to investigate the role of socio-demographic, life-style and clinical risk factors of low birth weight (LBW) among pregnant women in Saudi Arabia. It is a hospital-based, case-control study of mothers of $135 \mathrm{LBW}$ and 65 normal birth weight neonates at the Obstetrics and Gynecology Unit of the Maternity and Children Hospital, KSA. Methods: On comparison by Duncan's test, the gestational age of three LBW groups was found to be significantly different $(P=$ 0.0026). The mean duration of hospital stay of the infants also increased for the LBW, very LBW and extreme LBW groups, and their difference was statistically significant $(P=0.0012)$. Results: A statistically significant, progressive decline was observed in the weight, length and circumference of the head of infants in the LBW to VLBW to ELBW groups. Conclusion: The present study has assessed the state of this significant public health problem of LBW in KSA, and identified several maternal modifiable risk factors. There is an urgent need for the development of reference charts using current data for the Middle Eastern population.

\section{Keywords}

Low Birth Weight, Neonates, Pregnant Women, Public Health

\section{Background}

Low birth weight (LBW) is a condition when a baby is born weighing less than 2500 grams. Some of the LBW babies are healthy, in spite of being small compared to anthropometric measures of normal babies. However, being a LBW baby can cause serious health problems during neonatal stage, and later in their life, if the baby gets adequate 
treatment and nourishment to survive through the childhood [1]. There are two main reasons for the birth of LBW babies: (i) pre-term birth and (ii) foetal growth restriction in the womb of the mother, also called intra-uterine growth restriction (IUGR). Premature babies are born within 37 weeks of pregnancy, leading to lower birth weight. In the case of foetal growth restriction, the baby does not gain weight due to several reasons, including that parents themselves may be small and underweight. Apart from this, foetal growth restriction may be caused by birth defects or infections that slow down or stop the growth of the baby in the womb. In addition, there are certain medical and lifestyle-related risk factors in mothers that can induce pre-term labor (before 37 weeks of pregnancy) and/or cause the babies to be born with LBW. Chronic health conditions like high blood pressure, diabetes, heart, lung and kidney problems, and infections in the uterus can lead to LBW. Problem with the placenta that reduces the flow of blood and nutrients can limit foetal growth. Smoking, consumption of alcohol, use of recreational drugs and abuse of prescription drugs during pregnancy can affect the growth of the baby in the womb and increase the chances of premature birth and birth defects. Teenage (less than 17 years) and late pregnancies (35 years and above) have a higher chances of leading to LBW babies [1].

LBW is one of the main predictors of infant mortality. The global incidence of LBW is around $17 \%$, although estimates vary from $19 \%$ in the developing countries, where it is an important public health problem, to $5 \%-7 \%$ in the developed countries [2]. In the United States, about 1 in every 12 babies is born with LBW and about 1 in 10 is born prematurely. About 13 percent of African-American babies are born with low birth weight each year. The incidence rate of LBW births for other races/ethnicities in the US was 8.4 percent of Asian babies, 7.6 percent of Native American babies, and about 7 percent for Hispanic and white babies [3]. A study by the Agency for Healthcare Research and Quality (AHRQ) found that among 3.8 million births that occurred in the United States in 2011, approximately 6.1\% (231,900) were diagnosed with LBW $(<2500$ g). Approximately 49,300 newborns (1.3\%) weighed less than 1500 grams (VLBW) [4].

LBW babies are more likely than babies with normal weight to have health problems, as a newborn as well as later in life. Some babies need special care in the neonatal intensive care unit, to survive and develop into healthy weight range. Most common problems of LBW and premature babies at the neonatal stage are: Respiratory distress syndrome (RDS) due to the absence of surfactant protein to keep air sacs in lungs from collapsing; Intraventricular hemorrhage (IVH) in the brain; Patent ductusarteriosus (PDA), a common heart problem where this artery does not close after birth so that baby's blood can pass through the lungs for oxygenation, leading to heart failure; and Necrotizing enterocolitis (NEC) due to infection or even damage to the intestine [3]. Later in life, LBW babies can develop diabetes, high blood pressure, heart disease, developmental disabilities and neurological disorders like cerebral palsy and autism [1] [3].

The prevalence of low birth weight in the Middle East and North African region is estimated to be $11 \%$ which highlights the gravity of the situation [5]. There is a paucity 
of data on LBW births and its risk factors in the Kingdom of Saudi Arabia (KSA). The purpose of the present study is to investigate the role of maternal socio-demographic, life-style, health care behavioral, and clinical risk factors of LBW among pregnant women, with a long term objective to improve the quality of the health of the mothers, fetuses, infants and children in KSA.

\section{Patients and Methods}

The present hospital-based, case-control study was conducted at the Obstetrics and Gynecology Unit of the Maternity and Children Hospital in Makkah, KSA, under the approval of the Institutional Review Board (IRB). The study was conducted between October and December 2014. The sample size for the study was calculated to be 200, and accordingly, mothers of the 200 LBW neonates delivered in the Obstetrics Unit of the hospital were included in the study. Inclusion criteria for LBW neonates consisted of availability of information about exact duration of amenorrhea (the first day of the last menstrual period reported by the mother was used to calculate the gestational age at the time of delivery, or mothers may have had estimates of gestational age derived by ultrasound measurement made at antenatal care); mother's willingness to participate in the study; and availability of suitable matched normal weight control. If any of the above criteria was not fulfilled, the neonate was not included in the study. The purpose of the study and procedures to be performed were explained to all mothers, confidentiality was assured, and consent to participate in the study was taken accordingly.

Data were collected on 200 infants divided into four categories: 45 cases of low birth weight (LBW) neonates who weigh between $1500 \mathrm{~g}$ and $2500 \mathrm{~g}, 45$ cases of very low birth weight (VLBW) infants who weigh between $1000 \mathrm{~g}$ to $1500 \mathrm{~g}, 45$ cases of extremely low birth weight (ELBW) infants who weigh less than $1000 \mathrm{~g}$, and 65 normal birth weight neonates (NBW) chosen randomly. Data were collected from birth until discharge of neonates from the hospital. To obtain sufficient data, nutritional practices and other aspects of neonatal care were not altered by the study protocol.

A questionnaire specially designed to collect information on variables relating to the study was used. A pilot study was conducted to test the feasibility and validity of the questionnaire, and necessary corrections were incorporated. The mothers with LBW and NBW neonates were also interviewed. General physical examination was performed for all mothers with LBW and NBW neonates. Anthropometric measurements of mothers-height and weight-were measured while the women wore light outer garments, but not shoes. Weight gained during pregnancy was calculated by subtracting the weight of the mother before pregnancy or weight at $\leq 12$ weeks of gestation, from her weight at labor. Body mass index (BMI) was calculated as weight divided by height squared $\left(\mathrm{kg} / \mathrm{m}^{2}\right)$ using her weight before pregnancy or $\leq 12$ weeks of gestation.

Anthropometric measurements of the infant included weight, length, and head circumference. Body weight was recorded daily from infant birth until discharge from the hospital or until normal birth weight was achieved. LBW neonates were also classified as small (SGA), appropriate (AGA) and large (LGA) for their gestational age, in terms 
of weight for their gestational age in weeks. The growth velocity of the neonates was calculated according to the equation given by Aloka et al. [6]:

$$
\text { Growth Velocity }(\mathrm{GV})=\left[1000 \times \ln \left(\mathrm{W}_{\mathrm{n}} / \mathrm{W}_{1}\right)\right] /\left(\mathrm{D}_{\mathrm{n}}-\mathrm{D}_{1}\right)
$$

where, $\mathrm{W}_{\mathrm{n}}$ and $\mathrm{W}_{1}$ are the weight of the infant on the day of discharge $\left(\mathrm{D}_{\mathrm{n}}\right)$ and the day of delivery $\left(D_{1}\right)$, respectively.

\section{Statistical Analysis}

Descriptive statistics was determined for all clinical and anthropometric parameters of the mothers and infants, and expressed as Mean \pm SD. Odds ratio (OR) with $95 \%$ confidence interval (CI) or exact confidence limits (ECL) was used as the test of significance. Also, stepwise regression analysis was applied to find out the weight of risk factors and effect of the potential confounders. In stepwise regression, adjusted partial $\mathrm{F}$ test was used to determine the significance level. Analysis of Variance (ANOVA) was performed with SAS software (Statistic Analysis System) version 9.1 (SAS Institute Inc., Cary NC). Pearson test was used for the comparison of differences and relation between two or more parameters. $P<0.05$ is considered statistically significant according to Duncan test.

\section{Results}

The demographic characteristics and anthropometric parameters of the mothers, probably associated with the birth of LBW infant are shown in Table 1. In both LBW and NBW groups, $80 \%-90 \%$ of the mothers were married at age $>18$ years. However, $\sim 20 \%$ in the LBW group had their age at marriage of $<18$ years, compared to $\sim 11 \%$ in the NBW group.

Out of 135 LBW mothers, 33 (24.4\%) were shorter than $145 \mathrm{~cm}$, while only 6 (9.2\%) were shorter in the NBW group. Considering the weight of mothers, 25 (18.5\%) mothers of LBW neonates weighed $<45 \mathrm{~kg}$ before or at early pregnancy as well as $<55 \mathrm{~kg}$ at delivery. BMI of $<18$ and $18-22$ represent malnutrition and underweight status of the subjects. There were $6.7 \%$ and $12.6 \%$ of such mothers in the LBW group, while $1.5 \%$ and $6.2 \%$ were present in the NBW group. $33.3 \%$ of the subjects in the LBW group had a maternal family history of birth of LBW babies compared to $13.8 \%$ in the NBW group.

Gestational characteristics of mothers of LBW and NBW neonates that belong to the four groups, namely, LBW, VLBW, ELBW and NBW are presented in Table 2.

The gestational age of the neonates of the NBW group was $37.4 \pm 4.2$ (Mean \pm SD) weeks, and it decreased successively for the LBW, VLBW and ELBW groups indicating premature birth of the infants. On comparison by Duncan's test, the gestational age of three LBW groups were found to be significantly different $(P=0.0026)$. Consequent to premature birth and low birth weight, there was high mortality rate of the infants in the LBW, VLBW and ELBW groups, as indicated by the survival rate in Table 2. Only $26.6 \%$ of the infants with ELBW survived, compared to $86.6 \%$ and $100 \%$ of the infants in the VLBW and LBW groups, respectively. The mean duration of hospital stay of the 
Table 1. Demographic characteristics of mothers of LBW and NBW neonates.

\begin{tabular}{|c|c|c|c|c|}
\hline \multirow{2}{*}{$\begin{array}{c}\text { Demographic } \\
\text { characteristics/risk factors }\end{array}$} & \multicolumn{2}{|c|}{$\begin{array}{l}\text { Mother's with NBW neonate } \\
\qquad(\mathrm{n}=65)\end{array}$} & \multicolumn{2}{|c|}{$\begin{array}{l}\text { Mother's with LBW neonate } \\
\qquad(\mathrm{n}=135)\end{array}$} \\
\hline & No. & $\%$ & No. & $\%$ \\
\hline \multicolumn{5}{|l|}{ Age at marriage (years) } \\
\hline$\leq 18$ & 7 & 10.7 & 26 & 19.3 \\
\hline$>18$ & 58 & 89.3 & 109 & 80.7 \\
\hline \multicolumn{5}{|l|}{ Height $(\mathrm{cm})$} \\
\hline$\leq 145$ & 6 & 9.2 & 33 & 24.4 \\
\hline$>145$ & 59 & 90.8 & 102 & 75.6 \\
\hline \multicolumn{5}{|c|}{ Weight before/at early pregnancy (kg) } \\
\hline$\leq 45$ & 5 & 7.7 & 25 & 18.5 \\
\hline$>45$ & 60 & 92.3 & 110 & 81.5 \\
\hline \multicolumn{5}{|l|}{ Weight at delivery $(\mathrm{kg})$} \\
\hline$\leq 55$ & 5 & 7.7 & 25 & 18.5 \\
\hline$>55$ & 60 & 92.3 & 110 & 81.5 \\
\hline \multicolumn{5}{|l|}{ Body mass index $(\mathrm{BMI})\left(\mathrm{kg} / \mathrm{m}^{2}\right)^{*}$} \\
\hline Malnutrition: $<18$ & 1 & 1.5 & 9 & 6.7 \\
\hline Underweight: $18-<22$ & 4 & 6.2 & 17 & 12.6 \\
\hline Normal: $22-<25$ & 50 & 76.9 & 94 & 69.6 \\
\hline Obese: 25 - 30 & 10 & 15.4 & 15 & 11.1 \\
\hline \multicolumn{5}{|c|}{ Maternal family history of LBW babies } \\
\hline Yes & 9 & 13.8 & 45 & 33.3 \\
\hline No & 56 & 86.2 & 90 & 66.6 \\
\hline
\end{tabular}

${ }^{*}$ BMI before/at early pregnancy.

Table 2. Gestational characteristics of mothers of LBW and NBW neonates.

\begin{tabular}{cccccc}
\hline Gestational parameter & $\begin{array}{c}\text { NBW } \\
(\mathrm{n}=65)\end{array}$ & $\begin{array}{c}\text { LBW } \\
(\mathrm{n}=45)\end{array}$ & $\begin{array}{c}\text { VLBW } \\
(\mathrm{n}=45)\end{array}$ & $\begin{array}{c}\text { ELBW } \\
(\mathrm{n}=45)\end{array}$ & $P$ value \\
\hline Gestational age (weeks) & $37.4 \pm 4.2$ & $36.1 \pm 2.8^{\mathrm{a}}$ & $32.8 \pm 3.9^{\mathrm{ab}}$ & $29.5 \pm 3.0^{\mathrm{b}}$ & 0.0026 \\
Survival (\%) & 100 & 100 & 86.6 & 26.6 & - \\
SGA (\%) & 0 & 0 & 53.8 & 25 & - \\
AGA (\%) & 100 & 80 & 38.5 & 75 & - \\
LGA (\%) & 0 & 20 & 7.7 & 0 & - \\
Length of hospital stay* (days) & $3.2 \pm 1.3$ & $8.5 \pm 0.7^{\mathrm{b}}$ & $36.8 \pm 12.0^{\mathrm{a}}$ & $25 \pm 7.6^{\mathrm{ab}}$ & 0.0012 \\
\hline
\end{tabular}

${ }^{*}$ Mean $\pm \mathrm{SD}$. ${ }^{\mathrm{a}}, \mathrm{b},{ }^{\mathrm{ab}}$ Means with different superscripts are significantly different $(P<0.05)$ according to Duncan’s test. 
infants also increased for the LBW, VLBW and ELBW groups, and their difference was statistically significant $(P=0.0012)$. Most of the LBW $(80 \%)$ and ELBW $(75 \%)$ infants had appropriate weight for their gestational age (AGA) while about half of the VLBW infants (53.8\%) were small for their gestational age (SGA). VLBW group had highest percent of SGA while LBW group had the lowest percent. LBW group had highest percentage of AGA infants while very few infants of VLBW were classified as AGA. Finally, LBW showed highest percent of LGA while ELBW showed lowest percent.

Anthropometric measures of the neonates in each group are listed in Table 3 as Mean \pm SD.

As expected, a progressive decline is observed in the weight, length and circumference of the head of infants in the LBW to VLBW to ELBW groups. Using Duncan's multiple comparison tests, the differences in weight, length, and head circumference for the three LBW groups were found to be statistically significant, as seen by the $P$ values in Table 3.

Several socio-demographic characteristics of mothers of LBW infants were found to be considerably different compared to their NBW counterparts, as shown in Table 1. Based on the disparity, these factors were considered as risk factors for the birth of LBW infants and the odds ratio (OR) for each of these factors were calculated. OR and the corresponding $95 \%$ confidence intervals for the socio-demographic risk factors of mothers are listed in Table 4.

Table 3. Anthropometric measurements of neonates at birth.

\begin{tabular}{cccccc}
\hline Anthropometric parameter & $\begin{array}{c}\text { NBW } \\
(\mathrm{n}=65)\end{array}$ & $\begin{array}{c}\text { LBW } \\
(\mathrm{n}=45)\end{array}$ & $\begin{array}{c}\text { VLBW } \\
(\mathrm{n}=45)\end{array}$ & $\begin{array}{c}\text { ELBW } \\
(\mathrm{n}=45)\end{array}$ & $P$ value \\
\hline Weight $(\mathrm{kg})$ & $3.64 \pm 0.12$ & $2.1 \pm 0.25^{\mathrm{a}}$ & $1.29 \pm 0.16^{\mathrm{b}}$ & $0.93 \pm 0.03^{\mathrm{c}}$ & $<0.0001$ \\
Height $(\mathrm{cm})$ & $49.32 \pm 4.24$ & $47.53 \pm 2.88^{\mathrm{a}}$ & $42.53 \pm 5.05^{\mathrm{b}}$ & $35.25 \pm 1.70^{\mathrm{c}}$ & $<0.0001$ \\
Head circumference $(\mathrm{cm})$ & $34.62 \pm 32.17$ & $31.4 \pm 1.7^{\mathrm{a}}$ & $29.57 \pm 4.5^{\mathrm{ab}}$ & $26.25 \pm 2.06^{\mathrm{b}}$ & 0.0241 \\
\hline
\end{tabular}

${ }^{*}$ All the parameters are given as Mean $\pm \mathrm{SD}$. ${ }^{\mathrm{a}}, \mathrm{b},{ }^{\mathrm{c}},{ }^{\text {ab }}$ Means with different superscripts are significantly different $(P<$ $0.05)$ according to Duncan's test.

Table 4. Socio-demographic risk factors for the birth of LBW neonates.

\begin{tabular}{clc}
\hline Risk factor & OR & 95\% CI \\
\hline Age at marriage $(\leq 18$ years $)$ & 2.1 & $1.2-3.7$ \\
Height $(\leq 145 \mathrm{~cm})$ & 3.3 & $1.9-5.7$ \\
Weight before/at early pregnancy $(\leq 45 \mathrm{~kg})$ & 2.4 & $1.3-4.3$ \\
Weight at delivery $(\leq 55 \mathrm{~kg})$ & 2.7 & $1.5-5.0$ \\
BMI $\left(<18 \text { and } 18-22 \mathrm{~kg} / \mathrm{m}^{2}\right)^{*}$ & 5.1 & $1.6-21.3^{* *}$ \\
Family history of LBW babies & 2.7 & $1.3-5.7$ \\
Low educational status & 1.7 & $1.2-2.5$ \\
Unskilled occupation & 1.6 & $1.1-2.4$ \\
\hline
\end{tabular}

${ }^{*}$ BMI before/at early pregnancy; ${ }^{* *}$ Exact confidence limits (ECL). 
The OR is a useful measure to compare the magnitude of risk factors for the birth of LBW infants [7]. As observed from Table 4, the range of BMI indicating malnutrition and underweight status of mothers is the most severe risk factor $(\mathrm{OR}=5.1$, Exact Confidence Limits 1.6 - 21.3) for the birth of LBW infant. Although height and weight before/at early pregnancy are included in the calculation of BMI, these are also individual risk factors with OR of 3.3 (95\% CI 1.9 - 5.7) and 2.4 (95\% CI $1.3-4.3$ ), respectively. Mother's weight at delivery being $<55 \mathrm{~kg}$ and a maternal family history of LBW infants are also serious risk factors with similar OR of 2.7. Other social factors such as early marriage ( $<18$ years), lower education and unskilled occupation were among the factors with low risk for LBW infants (OR 2.1, 1.7 and 1.1 respectively).

\section{Discussion}

Prevalence of low birth weight in the present prospective study, an attempt has been made to understand maternal factors that influence the birth of LBW infants in the KSA. As mentioned, there are not many studies pertaining to the birth of LBW infants in the KSA or the Middle Eastern region, and hence, comparison of the results has to be made with similar studies predominantly from the Western countries.

The gestational age of LBW, VLBW and ELBW infants were 36, 32.7 and 29.5 weeks, respectively. These results demonstrate that the infant's birth weight diminished with a decrease in their gestational age. These results are slightly higher than those of Ehrenkranze et al. [8] who have reported that GA for VLBW was 28.5 to 30.9 weeks, and for ELBW was 24.8 - 27.6 weeks. Other researchers have merely reported that GA for LBW is less than 37 weeks [9] [10].

The survival percentage for LBW, VLBW and ELBW infants are $100 \%, 86.6 \%$ and $26.6 \%$, respectively, indicative of significant decrease in their survival with reducing birth weight. Ehrenkranze et al. [8] have observed a survival rate of 98.8 to $100 \%$ for VLBW and $63.9 \%$ to $91.6 \%$ for ELBW infants which are significantly higher, especially for the ELBW group. This could be attributed to the type and quality of antenatal care. The survival percentage for ELBW was 1\% in 1960, 40\% in 1985 and $80 \%$ in 2000 year in the United States [10]. With the advancement in medical technology and availability of the facilities in the United States, there has been a dramatic improvement in the survival rate of LBW infants.

On classification of newborns in the present study, there were high percentage of SGA infants in the VLBW and ELBW groups, 53.8\% and 25\%, respectively (Table 2). These results closely match the studies by Trebar et al. who reported 55.3\% SGA at birth for VLBW $(\mathrm{N}=1320)$, and Saigal et al. who reported 20\% - 28\% for ELBW groups $(\mathrm{N}=147)$ [11] [12]. The results of a recent study of VLBW infants by Lima et al. were slightly lower than our results (33\% SGA, N = 570) [13].

Several studies have examined the association between maternal pre-pregnancy nutrition and birth size of the infant, as reported by a recent systematic review [14]. In the present study, pre-pregnancy BMI reflecting malnutrition/underweight status of the mother was found to be a severe risk factor. Liu et al. have reported an increased risk of 
delivering a SGA infant (adjusted RR: 1.7 [95\% CI 1.1, 2.6]) among underweight women $\left(\mathrm{BMI}<18.5 \mathrm{~kg} / \mathrm{m}^{2}\right)$ in a retrospective study of Chinese women [15]. Ronnenberg et al. have also reported similar findings, and additionally found that the infants are at increased risk for fetal growth deficits [16]. Being underweight was also associated with smaller infant head circumference. Another large prospective study from Vietnam also reported a significantly higher risk of delivering a SGA infant (adjusted OR: 1.95 [95\% CI 1.52 - 2.50], $P<0.01$ ) among women who were underweight before conception [17]. The WHO collaborative study on maternalanthropometry and pregnancy outcomes, using data from 111,000 women from across the world reported that mothers in the lowest quartile of pre-pregnancy weight carried an elevated risk of IUGR and LBW of 2.55 (95\% CI 2.3, 2.7) and 2.38 (95\% CI 2.1, 2.5) respectively, compared to the upper quartile [18]. In addition to maternal $\mathrm{BMI}<18 \mathrm{~kg} / \mathrm{m}^{2}(\mathrm{AOR}=6.7 ; 95 \% \mathrm{CI}=1.21$ $37.14)$, maternal height $<1.5 \mathrm{~m}(\mathrm{AOR}=3.7 ; 95 \% \mathrm{CI}=1.22-11.28)$ was a risk factor in a recent study from Ethiopia [19].

The percentage of infants having weight appropriate for gestational age (AGA) in LBW, VLBW and ELBW groups were $80 \%, 38.46 \%$ and $75 \%$, respectively (Table 2). However, the SGA, AGA and LGA percentages for the overall LBW sample were found to be $25.9 \%, 64.5 \%$ and $9.6 \%$, respectively. Similar observations have been made by Hediger et al. and Rao, Georgieff who indicated that a majority of the infants, $80.9 \%(\mathrm{~N}=$ 4431) and 74\% were AGA [20] [21]. The LGA percentages in these studies were also similar at 10.5 and $11 \%$, not very different from the present study $(9.6 \%)$.

Hospitalization time is considered as an indicator of severity in preterm infants, and it is probably reflected as weight gain [22]. The mean length of hospital stay of infants in the three groups was $8.46,36.84$ and 25 days, respectively, showing longer antenatal care for VLBW and ELBW babies. Ghadimi et al. have reported that the duration of care is related to the type and duration of parenteral nutrition that is high in both calorie $(80 \mathrm{kcal} / 100 \mathrm{ml})$ and high protein milk $(2.8 \mathrm{~g} / 100 \mathrm{ml})$ that is needed to gain weight [23]. In their study, hospital stay for VLBW and ELBW was 46 (22 - $80 \mathrm{~d}$ ) and 72 (58 93 d) days, respectively. These infants regained the expected birth weight in 10 (2 - 23 d) and 17 (14 - $30 \mathrm{~d})$ days, respectively.

The GV for ELBW neonates was the highest at $20 \mathrm{~g} / \mathrm{kg} / \mathrm{d}$, and was almost equal for the other two groups (LBW 8.74, VLBW $8.71 \mathrm{~g} / \mathrm{kg} / \mathrm{d}$ ). Ehrenkranze et al. have reported higher GV for VLBW (15.2 - $16.0 \mathrm{~g} / \mathrm{kg} / \mathrm{d})$, but lower GV for ELBW infants (13.9 - 14.6 $\mathrm{g} / \mathrm{kg} / \mathrm{d}$ ) [8]. However, a study from the US, and another in multi-hospital system have concluded that the GV of LBW infants ranged from 14.8 to $15.0 \mathrm{~g} / \mathrm{kg} / \mathrm{d}$ [10] [24]. In a recent cross-sectional study of hospital nutrition support of LBW infants in KSA by Azzeh et al., GV of LBW infants ranged from 8.7 to $10.2 \mathrm{~g} / \mathrm{kg} / \mathrm{d}$, which were not statistically significant $(P>0.05)$ [25]. These results based on the same geographical location and population matches with the present study, especially for LBW and VLBW infants, but GV for the ELBW group is significantly lower. However, Azzeh et al. have attributed the low GV to the use of low protein $(1.5 \mathrm{~g} / \mathrm{kg} / \mathrm{d})$ and low calorie $(105 \mathrm{kcal} / \mathrm{kg} / \mathrm{d})$ nutrition formula for all infants irrespective of their birth weight. ELBW showed the 
highest value in WBC (20.23 unitsg/dl) as compared with other infants, which could be due to acute infection or malignancy. As far as hematological parameters, ELBW showed low hemoglobin (11.93 units $\mathrm{g} / \mathrm{dl}$ ) and RBC (3.39 units million/milliliter), which might be an indication of anemia, iron deficiency, folic acid and/or vitamin B12 deficiencies, and blood loss or over-hydration. ELBW infants also showed the highest calcium concentration compared to other groups. In addition, ELBW showed the highest sodium (157.33 units $\mathrm{mg} / \mathrm{dI}$ ) on the day of delivery, and decreased to the lowest value (132.3 units $\mathrm{mg} / \mathrm{dI}$ ) on the day of discharge, which may be related to high stool and urine output. Most enteral nutrition formulas are low in sodium content and patients solely dependent on enteral nutrition may develop low sodium levels. ELBW showed slightly low level in $\mathrm{Mg}$ (1.7 units $\mathrm{mg} / \mathrm{dI}$ ), along with potassium and phosphorus, on the last day resulting in respiratory and, cardiac instability or muscle weakness [26].

Age at marriage ( $\leq 18$ years) is an important risk factor for LBW in the present study $(\mathrm{OR}=2.1,95 \%$ CI 1.2 - 3.7). Similar risk of delivering LBW or VLBW infant is higher for the teenagers and the older women (aged $35 \mathrm{yr}$ and more) has been observed in several studies. In a study from Korea, the rate of LBW, VLBW, and ELBW infants born to teenage mothers were $18.6 \%, 3.2 \%, 1.7 \%$, respectively, which were about two times higher than those of infants with maternal age $20-34$ years $(7.2 \%, 1.4 \%$, and $0.7 \%(P<0.001))$. Infants whose mothers aged 35 years and more also showed higher LBW, VLBW, ELBW rates higher than those of infants with maternal age between 20 and $34 \mathrm{yr}(10.6 \%, 2.7 \%, 1.2 \%, P<0.001)$ [27]. LBW was also found to be associated with maternal age of less than 20 years and low level of maternal education in a previous study from China ( $\mathrm{OR}=1.332,95 \% \mathrm{CI} 1.04-1.69$ ) [28]. Maternal age at delivery of $<20$ years (adjusted odds ratio $(\mathrm{AOR})=3 ; 95 \% \mathrm{CI} 1.65-5.73$ ) has also been observed as a risk factor in a recent study from Southeast Ethiopia [19].

In the Kingdom of Saudi Arabia (KSA), the basic infant ( $<1$ year) mortality rate has improved from 34 to 8 (per 1000 live births) in the last two decades, and neonatal $(<28$ days) mortality rate for 2011 has been estimated to be 5 per 1000 live births [29]. Improvement may be a result of synergisitic effects of improved food intake, food supplementation, improved micronutrient intake, education and the environment of the pregnant woman and her family. Nevertheless, the prevalence of LBW births in the Middle Eastern population is relatively high [5]. Towards alleviating this significant public health problem, present small cross-sectional study has assessed the state of the problem and identified several maternal modifiable risk factors which can be resolved to improve the situation of the newborn, and avoid long term consequences of LBW.

\section{Conclusion}

The present study has several limitations in addition to being small and preliminary. For the classification of SGA, AGA and LGA, anthropometric data are compared with reference charts for gestational age. Ideally, up-to-date reference data from the same or a similar population are required [30]. The choice of the reference population has a 
considerable impact on the classification, especially for preterm infants [31]. Therefore, there is an urgent need for the development of reference charts using current data for the Middle Eastern population.

\section{Competing Interests}

None of the authors have any competing interests.

\section{Author's Contribution}

AA and NES equally contributed to the study. Both the authors read and approved the final manuscript.

\section{Funding}

None of the author received any funding for the research/publication of this study.

\section{Declaration}

Ethical approval of this study was obtained from the Institutional Review Board (IRB) of the Maternity and Children Hospital in Makkah, KSA.

\section{References}

[1] Centers for Disease Control National Center for Environmental Health, Environmental Health Tracking Branch (2012) Low Birth Weight and the Environment. http://ephtracking.cdc.gov/showRbLBWGrowthRetardationEnv.action

[2] de Bernabé, J.V., Soriano, T., Albaladejo, R., Juarranz, M., Calle, M.E., Martínez, D., et al. (2004) Risk Factors for Low Birth Weight: A Review. European Journal of Obstetrics \& Gynecology and Reproductive Biology, 116, 3-15. http://dx.doi.org/10.1016/j.ejogrb.2004.03.007

[3] March of Dimes (2014) Low Birthweight. http://www.marchofdimes.org/complications/low-birthweight.aspx

[4] Kowlessar, N.M., Jiang, H.J. and Steiner, C. (2013) Hospital Stays for Newborns, 2011. HCUP Statistical Brief \#163. Agency for Healthcare Research and Quality, Rockville. http://www.hcup-us.ahrq.gov/reports/statbriefs/sb163.pdf

[5] United Nations Children's Fund (2003) State of the World's Children Report, 2003. UNICEF, New York.

[6] Patel, A.L., Engstrom, J.L., Meier, P.P. and Kimura, R.E. (2005) Accuracy of Methods for Calculating Postnatal Growth Velocity for Extremely Low Birth Weight Infants. Pediatrics, 116, 1466-1473. http://dx.doi.org/10.1542/peds.2004-1699

[7] Szumilas, M. (2010) Explaining Odds Ratios. Journal of the Canadian Academy of Child and Adolescent Psychiatry, 19, 227-229.

[8] Ehrenkranz, R.A., Younes, N., Lemons, J.A., Fanaroff, A.A., Donovan, E.F., Wright, L.L., et al. (1999) Longitudinal Growth of Hospitalized Very Low Birth Weight Infants. Pediatrics, 104, 280-289. http://dx.doi.org/10.1542/peds.104.2.280

[9] Ramakrishnan, U. (2004) Nutrition and Low Birth Weight: From Research to Practice. American Journal of Clinical Nutrition, 79, 17-21.

[10] Goldenberg, R.L. and Culhane, J.F. (2007) Low Birth Weight in the United States. American 
Journal of Clinical Nutrition, 85, 584S-590S.

[11] Trebar, B., Traunecker, R., Selbmann, H.K. and Ranke, M.B. (2007) Growth during the First Two Years Predicts Pre-School Height in Children Born with Very Low Birth Weight (VLBW): Results of a Study of 1,320 Children in Germany. Pediatric Research, 62, 209-214. http://dx.doi.org/10.1203/PDR.0b013e3180ca7c5b

[12] Saigal, S., Stoskopf, B., Streiner, D., Paneth, N., Pinelli, J. and Boyle, M. (2006) Growth Trajectories of Extremely Low Birth Weight Infants from Birth to Young Adulthood: A Longitudinal, Population-Based Study. Pediatric Research, 60, 751-758. http://dx.doi.org/10.1203/01.pdr.0000246201.93662.8e

[13] Lima, P.A., de Carvalho, M., da Costa, A.C. and Moreira, M.E. (2014) Variables Associated with Extra Uterine Growth Restriction in Very Low Birth Weight Infants. Jornal de Pediatria (Rio ), 90, 22-27. http://dx.doi.org/10.1016/j.jped.2013.05.007

[14] Ramakrishnan, U., Grant, F., Goldenberg, T., Zongrone, A. and Martorell, R. (2012) Effect of Women's Nutrition before and during Early Pregnancy on Maternal and Infant Outcomes: A Systematic Review. Paediatric and Perinatal Epidemiology, 26, 285-301. http://dx.doi.org/10.1111/j.1365-3016.2012.01281.x

[15] Liu, X., Du, J., Wang, G., Chen, Z., Wang, W. and Xi, Q. (2011) Effect of Pre-Pregnancy Body Mass Index on Adverse Pregnancy Outcome in North of China. Archives of Gynecology and Obstetrics, 283, 65-70. http://dx.doi.org/10.1007/s00404-009-1288-5

[16] Ronnenberg, A.G., Wang, X., Xing, H., Chen, C., Chen, D., Guang, W., et al. (2003) Low Preconception Body Mass Index Is Associated with Birth Outcome in a Prospective Cohort of Chinese Women. Journal of Nutrition, 133, 3449-3455.

[17] Ota, E., Haruna, M., Suzuki, M., Anh, D.D., Tho, L.H., Tam, N.T.T., et al. (2011) Maternal Body Mass Index and Gestational Weight Gain and Their Association with Perinatal Outcomes in Vietnam. Bulletin of the World Health Organization, 89, 127-136. http://dx.doi.org/10.2471/BLT.10.077982

[18] World Health Organisation (1995) Maternal Anthropometry and Pregnancy Outcomes: A WHO Collaborative Study. Bulletin of the World Health Organization, 73, 1-98.

[19] Demelash, H., Motbainor, A., Nigatu, D., Gashaw, K. and Melese, A. (2015) Risk Factors for Low Birth Weight in Bale Zone Hospitals, South-East Ethiopia: A Case-Control Study. BMC Pregnancy and Childbirth, 15, 264. http://dx.doi.org/10.1186/s12884-015-0677-y

[20] Hediger, M.L., Overpeck, M.D., Maurer, K.R., Kuczmarski, R.J., McGlynn, A. and Davis, W.W. (1998) Growth of Infants and Young Children Born Small or Large for Gestational Age: Findings from the Third National Health and Nutrition Examination Survey. Archives of Pediatrics \& Adolescent Medicine, 152, 1225-1231. http://dx.doi.org/10.1001/archpedi.152.12.1225

[21] Rao, R. and Georgieff, M. (2005) Microminerals. In: Tsang, R.C., Uauy, R., Koletzko, B. and Zlotkin, S., Eds., Nutrition of Thepreterm Infant, Digital Educational Publishing Inc., Cincinnati.

[22] Claudet, I., De Montis, P., Debuisson, C., Maréchal, C., Honorat, R. and Grouteau, E. (2012) Analysis of Neonate Admissions to the Pediatric Emergency Department. Archives de Pédiatrie, 19, 900-906. http://dx.doi.org/10.1016/j.arcped.2012.06.016

[23] Ghadimi, H., Arulanantham, K. and Rathi, M. (1973) Evaluation of Nutritional Management of the Low Birth Weight Newborn. American Journal of Clinical Nutrition, 26, 473476.

[24] Christensen, R.D., Henry, E., Kiehn, T.I. and Street, J.L. (2006) Pattern of Daily Weights among Low Birth Weight Neonates in the Neonatal Intensive Care Unit: Data from a Mul- 
tihospital Health-Care System. Journal of Perinatology, 26, 37-43.

http://dx.doi.org/10.1038/sj.jp.7211431

[25] Azzeh, F.S., Alazzeh, A.Y., Dabbour, I.R., Jazar, A.S. and Obeidat, A.A. (2014) Effect of Hospital Nutrition Support on Growth Velocity and Nutritional Status of Low Birth Weight Infants. Nutricion Hospitalaria, 30, 800-805.

[26] DAA Nutrition Support Interest Group's NSW Chapter (2011) Enteral Nutrition Manual for Adults in Healthcare Facilities. Dietitians Association of Australia.

http://daa.asn.au/wp-content/uploads/2011/11/Enteral-nutrition-manual-Oct-2011.pdf

[27] Shin, S.M., Chang, Y.P., Lee, E.S., Lee, Y.-A., Son, D.-W., Kim, M.-H., et al. (2005) Low Birth Weight, Very Low Birth Weight Rates and Gestational Age-Specific Birth Weight Distribution of Korean Newborn Infants. Journal of Korean Medical Science, 20, 182-187. http://dx.doi.org/10.3346/jkms.2005.20.2.182

[28] Chen, Y., Li, G., Ruan, Y., Zou, L., Wang, X. and Zhang, W. (2013) An Epidemiological Survey on Low Birth Weight Infants in China and Analysis of Outcomes of Full-Term Low Birth Weight Infants. BMC Pregnancy and Childbirth, 13, 242.

http://dx.doi.org/10.1186/1471-2393-13-242

[29] United Nations Children's Fund (2013) State of the World's Children Report. UNICEF, New York.

[30] Bertino, E., Milani, S., Fabris, C. and De, C.M. (2007) Neonatal Anthropometric Charts: What They Are, What They Are Not. Archives of Disease in Childhood-Fetal and Neonatal Edition, 92, F7-F10. http://dx.doi.org/10.1136/adc.2006.096214

[31] Hemming, K., Hutton, J.L., Glinianaia, S.V., Jarvis, S.N. and Platt, M.J. (2006) Differences between European Birthweight Standards: Impact on Classification of "Small for Gestational Age". Developmental Medicine and Child Neurology, 48, 906-912. http://dx.doi.org/10.1017/S0012162206001988 


\section{Abbreviations}

LBW: Low Birth Weight;

IUGR: Intra-Uterine Growth Restriction;

RDS: Respiratory Distress Syndrome;

IVH: Intraventricular Hemorrhage;

PDA: Patent Ductus Arteriosus;

NEC: Necrotizing Enterocolitis;

KSA: Kingdom of Saudi Arabia;

IRB: Institutional Review Board;

VLBW: Very Low Birth Weight;

ELBW: Extremely Low Birth Weight;

NBW: Normal Birth Weight Neonates;

BMI: Body Mass Index;

SGA: Small Gestational Age;

AGA: Appropriate Gestational Age;

LGA: Large Gestational Age;

CI: Confidence Interval;

ECL: Exact Confidence Limits;

ANOVA: Analysis of Variance.

Submit or recommend next manuscript to SCIRP and we will provide best service for you:

Accepting pre-submission inquiries through Email, Facebook, LinkedIn, Twitter, etc.

A wide selection of journals (inclusive of 9 subjects, more than 200 journals)

Providing 24-hour high-quality service

User-friendly online submission system

Fair and swift peer-review system

Efficient typesetting and proofreading procedure

Display of the result of downloads and visits, as well as the number of cited articles

Maximum dissemination of your research work

Submit your manuscript at: http://papersubmission.scirp.org/

Or contact arsci@scirp.org 